\title{
Análisis descriptivo de la programación televisiva infantil en Chile
}

\section{Descriptive Analysis of Children Television Programming in Chile}

\author{
Daniela Liendo \\ Verónica Torres \\ Universidad de Chile \\ danielaliendo@yahoo.es
}

\section{Resumen}

Una mirada que atraviese la programación televisiva infantil, dentro de la oferta de la televisión abierta y la televisión por cable; que intente describirla y categorizarla de acuerdo a distintas variables y que busque una relación entre dicha descripción y categorización con las dinámicas propias de la vida cotidiana de los infantes y su entorno, es lo que busca exponer el presente artículo.

Palabras clave: Infancia, televisión, Chile

\begin{abstract}
A look across children television programs, including open and pay television broadcast; the attempt to describe and categorize that TV programming according to different variables and seek relationships between this description and the daily life of children and their environment; those are the purposes of this paper.
\end{abstract}

Keywords: Children, Television, Chile 


\section{Introducción}

Según un estudio estadístico del Consejo Nacional de Televisión, respecto al consumo de medios por los niños, una de las actividades preferidas por los niños en los días de semana es ver televisión. Esto es, la Televisión en todos los segmentos socioeconómicos, con o sin TV Cable, y cualquiera sea el género, constituye un objeto de consumo cotidiano apreciado por los niños.

La televisión es un objeto que alcanza dimensiones mayores de las que cualquiera pueda creer. Como bien dice Morley (1996) en casi todos los hogares occidentales hay aparatos de televisión, lo cual transforma a este medio en uno de los componentes de nuestra vida diaria. Según Morley, la televisión es la vida cotidiana. Sus textos, sus imágenes, sus relatos son los "temas" de conversación que las personas tienen. Ahora bien, dentro de todos los elementos que integran este medio aparece la programación como una de las vías permeables de la información que la televisión tiene sobre sí misma. Quizás, en primera instancia, podría pensarse que la muestra de la parrilla programática corresponde a la manifestación de la existencia de una relación unilateral, donde uno de los polos le comunica a un otro indefenso, que debe acatar lo que allí se ofrece sin poder influir en el acto comunicativo. Sin embargo, y a medida que se analiza el fenómeno más detalladamente, la sentencia parece ser otra.

La programación está construida a partir de factores económicos, sociales y culturales. Estos establecen la seudo preferencia de los espectadores, lo que a la vez supone una relación bilateral. De este modo, es tal retroalimentación (entre el aparato TV y el espectador) la que hace complejo el fenómeno de la programación.

En este contexto, el estudio sintetizado describe aquellos principios constitutivos de la oferta programática infantil existente en TV abierta y TV pagada. Dicha oferta incorpora a los programas que conforman el bloque infantil en la parrilla programática de ambos estilos televisivos (exceptuando los de la televisión satelital debido a su falta de adhesión en los sectores urbanos). Entendiendo a la Televisión Abierta como todos aquellos canales de cobertura nacional que operan desde la Región Metropolitana. Respecto de la Televisión por Cable, fue analizada la parrilla programática de los canales que emiten sólo programación infantil. La investigación tomó en cuenta la oferta programática infantil expuesta durante las semanas de 12-18 de abril del año 2004, 19-25 de abril del año 2004, y del 26 de abril hasta el 2 de mayo del año 2004.

\subsection{Definición de variables}

1.1.1 Procedencia de los programas (nacionalidad): se trata del origen, en cuanto a nacionalidad, de los programas existentes dentro de la oferta infantil. En el presente estudio se analizan los programas de procedencia externa (extranjera) identificando el país de origen, y local (nacionales).

1.1.2 Género: Entendemos por este concepto a cualquier formato que tenga una identidad reconocida, de modo más o menos equivalente, por productores y consumidores, identidad que 
se ha establecido en el tiempo y que observa ciertas convenciones. En rigor, hemos advertido 5 categorías que componen la franja dedicada a los infantes: dibujos animados programas infantiles, programas en vivo, serie infantil, teleserie infantil.

1.1.3 Bloque horario: Para realizar una mejor descripción de la parrilla programática, la programación que se transmite diariamente fue dividida en cuatro bloques: madrugada, tarde, vespertino y nocturno. Con respecto a la descripción de los bloques horarios en la televisión por cable este no corre, ya que transmiten las 24 horas.

1.1.4 Publicidad: Dentro del gran espectro de publicidad, en el estudio se hace referencia, únicamente, a los productos auspiciadores pues son estos los que nos muestran una diferencia real en el tipo de publicidad. Se ha operacionalizado de acuerdo a cuatro conceptos: tipo de producto, capacidad de compra, rol prefigurado y cuadro de vida

\section{Observaciones a partir del estudio}

Una vez analizadas las distintas vertientes televisivas, el estudio muestra, a modo de conclusión, un diagnostico relativo a la constitución de la programación televisiva infantil en Chile. Luego, ante su pregunta inicial: ¿Cuáles son los principios constitutivos de la oferta programática infantil existente en TV abierta y TV. pagada? se encuentra con una realidad construida por varios principios, que en su interrelación logran un diagnóstico de cómo opera la programación televisiva infantil en Chile.

El enfrentamiento es ante un reconocimiento del fenómeno televisivo infantil, desde donde reconoceremos dos estadios: por una parte, la TV Pública y por otra, la TV de Mercado, o en la acepción de Fonnet, la TV de la oferta y la TV de la demanda, la cual se constituye con el quiebre de los programadores. Con respecto a ellos, se observa que, anteriormente, disponían de un stock de programas y su función consistía en escoger el mejor horario para poner en relación un programa con un público potencial, de acuerdo a criterios estéticos, políticos, económicos o culturales.

Con esto, se traslada a la Televisión de la demanda, sustentada en un cambio epistémico que apunta a programar en función de públicos, sus modos de vida e intereses, en el contexto de un espacio/horario concreto. Luego, la función del programador se remitirá a emitir un determinado programa en un universo de competencia, donde la emisión será siempre exhibida al público y, simultáneamente, a muchos otros programas en canales de "competencia”. De lo anterior, se deriva un principio claro que dice relación con que el programa no será emitido en función de sí mismo, sino de la audiencia, siendo ésta quien lo determine.

Observando los resultados del estudio en cuestión, podemos observar una correlación entre estos en la Televisión Abierta. Reconocemos, allí, síntomas relativos a su constitución. En primera 
instancia, respecto a la variable de procedencia, la primacía se divide entre Estados Unidos y Japón.

El análisis muestra que dos canales, Chilevisión y Megavisión, en el periodo de tiempo elegido para el estudio, centran su programación en producciones japonesas, pero esta tendencia se diluye en los días de fin de semana, ya que ambas estaciones dan mayor espacio a producciones estadounidenses. Dentro de estas acepciones, debemos considerar además la participación de TVN y TV-UC, quienes si bien carecen de programación infantil durante los días de semana, durante el fin de semana en el mismo periodo temporal, otorgan preponderancia a las producciones estadounidenses, con un $93 \%$ y $87 \%$ en ambos casos. Lo anterior, podría ser un síntoma por parte de la televisión abierta por reinstituir principios de la TV pública o de la oferta, de acuerdo a los cuales, y considerando la mayor carga de violencia que se presuponen que exhiben las producciones japonesas, retoma ciertas labores "educativas" o menos propensas a una apertura plena de este tipo de programas.

Respecto a las producciones nacionales, podemos decir algunas cosas observando los resultados del análisis en cuestión. Si bien Chile no es un país conocido por ser generador de programas destinados a un público infantil, los nuevos antecedentes presentados durante los últimos años pueden otorgar un quiebre a este juicio. Así, podemos ver una apuesta, de los diferentes canales de televisión, por otorgar espacio dentro de sus parrillas de programación a producciones nacionales destinadas a un público infantil. Dentro del periodo analizado por el estudio, esto se traduce a un $27 \%$ de los programas totales emitidos durante los días de semana y un 9\% durante el fin de semana. Dicha situación, a su vez, sitúa el síntoma de la TV pública en un contexto propenso a desarrollarse. En cuanto a la televisión por cable, podemos observar que, dentro del periodo temporal propuesto por el estudio, no existe una correlación con este fenómeno propio de la televisión abierta: la apertura a las producciones nacionales que recurran a una retórica infantil. Si observamos la nacionalidad de los programas emitidos por el cable, vemos que la predominan las producciones provenientes de Estados Unidos, seguida por Japón y luego Europa.

Otra observancia que nace del estudio, es que las diferencias relativas a programación, en la televisión por cable, no sugieren demasiadas líneas de ruptura, ya que la mayoría de los canales mantienen sus parrillas programáticas. Otro punto importante es señalar que las producciones estadounidenses, en estas estaciones televisivas, superan una participación del $80 \%$.

Respecto a la programación y la variable matutino/vespertino, la posible diferencia es más evidente en la TV abierta. La oferta programática de canales como Mega, Chilevisión y Red varía de acuerdo al bloque horario - en relación al público; la programación varía. Este síntoma lleva a intuir que dichas estaciones proponen la programación infantil, con respecto a los bloques horarios, de acuerdo al público al cual se enfocan, diferenciándolos por segmentos de edad. Se asume como una característica consustancial a las señales dado este aspecto.

En cuanto a la publicidad, de acuerdo a lo previsto en el estudio en cuestión, observamos que las categorías consideradas en el análisis permiten entretejer una caracterización de ella dentro del universo de la televisión infantil. En cuanto a la Televisión abierta, las diferentes estaciones no 
presentan rasgos homogéneos a la hora de abordar el tema publicitario. Se infiere que, en relación con el tipo de producto (en el que además comprenderemos el rol prefigurado y el cuadro de vida, características que en más del $90 \%$ de los casos se unen al tipo de producto) y la capacidad de compra, no habría una política homogénea dentro de la TV abierta. Esto propone una lectura sobre una probable ineficacia de marketing que choca con postulados cercanos a la TV pública en cuanto a programación y que éstos, en una medida importante, han determinado la constitución del espacio publicitario.

De acuerdo al estudio, en este sentido, la publicidad dentro de la Televisión por cable no presenta líneas más encauzadas que la mencionada. De acuerdo a esto, los distintos canales se moverían dentro de las opciones consideradas, sin mayor desarticulación de sus programaciones.

Al mismo tiempo, la investigación determina que no existe un correlato concreto entre los tipos de productos y la capacidad de compra de su supuesto público objetivo, ya que estas variables se entrecruzan dentro de las categorías seleccionadas sin una identificación clara y determinante, con lo cual, podemos señalar que el espacio publicitario de la televisión infantil, a un nivel general, no se articula de acuerdo a políticas objetivas, sino que en una medida importante, se presta como detonante del consumo global familiar o incluso como espacio disponible para alcanzar otros grupos sociales (no solo los niños) que puedan ser más determinantes como objetivo de consumo.

Luego, tomando en cuenta estos antecedentes pronunciados por la investigación en cuestión, una lectura indicaría que un síntoma de que estamos en un espacio no constituido aún, desde donde se mezclan visiones de la televisión pública con la de marketing. Podría suponerse que existiría una inversión de los papeles históricamente asignados tanto a la programación como a la publicidad, y que ha pasado de la predominancia del primero sobre el segundo, dentro del contexto de la televisión pública con sustrato ideológico, a una etapa de predominio de la publicidad, en el contexto de la televisión del marketing. Esto, puede ser considerado desde varias perspectivas. Una de ellas, se refiere a la constitución de la programación; ya que al estar en su mayoría constituida principalmente por productos de dos países (Estados Unidos y Japón), ha dejado de actuar con una finalidad concreta, para ejercer una fuerza por efecto de masividad. Esto se relaciona directamente con las determinantes que instaura la publicidad, nuevo centro de orden dentro del espacio televisivo, lo que siempre debe ser comprendido dentro de la etapa denominada "televisión del marketing". De ahí que las categorías de procedencia y los "síntomas" de TV pública justifiquen su existencia.

El espacio generado por la televisión hoy no permite una lectura unívoca, en tanto, sus pliegues direccionales mutan de acuerdo tanto a las variables del mercado como a la intencionalidad productiva de una televisión de "calidad", lo que además de limitar los juicios a ella referidos, supone la imposibilidad de categorizar sus tendencias; ellas existen, pero en una sociedad de comunicación expedita están en un estado de vulnerabilidad máxima.

Luego, de esta investigación es posible llegar al diagnóstico que dice que no hay un sólo principio hegemónico en la programación televisiva, sino que una interrelación de los ejes descritos, y lo único en común es la ausencia de un punto de vista que optimice al consumidor 
infantil desde el punto de vista publicitario, y la presencia de síntomas de un espacio de ensoñación respecto al lugar de la televisión publica, evidenciado en el hecho de que los canales de TV abierta no programen los días de fin de semana, sólo programación japonesa (como el resto de la semana), pues se entroncan con presuposiciones culturales.

Otro punto importante de los principios comunes de la programación es el carácter de ensoñación de las presuposiciones culturales, pues la programación descrita liga el marketing con la categoría del deber público, pero no hay fundamentación científica a las preocupaciones puestas en acto: específicamente no hay un saber concreto científico que liga la violencia a los dibujos animados japoneses, ni tampoco parece darse un manejo más sólido de los datos del consumidor concreto (en relación a la utilización de mercado), lo que hace que la investigación se constituya en un lugar privilegiado (desligada de la noción causa-efecto) para problematizar este tipo de realidades, que hacen ligar los datos de audiencia con la parrilla programática y con los contenidos concretos que se transmiten, lo que será materia viva para futuras investigaciones.

En resumen, la televisión hoy muestra distintas facetas, se encuentra a medio camino de asumir cualquier papel, de identificarse claramente con algún objetivo; y si bien se ratifica la necesidad de establecer nuevos criterios, ningún tipo de luz plena se cierne sobre ella. Sabemos que, como afirma Giselle Munizaga, "hoy en día es una verdad indiscutible que los medios industrializados no producen comunicación con una finalidad cultural, ni educativa, ni política" (1999: 13), y que al proyectar esa sombra sobre las emisiones infantiles, nos enfrentamos a una disyuntiva profunda respecto al papel que como mediadores nos toca en lo relativo a este tema.

De esta forma, "un reconocimiento básico y preliminar de la importancia que ha adoptado la televisión a la hora de contribuir a la producción de un imaginario social” (1999: 49) se inicia con el reconocimiento de sus principios constitutivos; cobrando mayor importancia cuando tal imaginario se expresa y absorbe desde los primeros años, de tal forma que el fenómeno televisivo no se evapore en injustificadas sospechas ni sustitutos comunicacionales, sino desde abajo, desde éste primer paso.

\section{Referencias}

Arancibia, J.P. (1999) "Acerca de decir, informar y objetivar". En: Ossa, C. (ed.) La pantalla delirante. Santiago de Chile: Arcis-LOM.

Balpe, J.P. (2003) "Hipertextualizaciones". Comunicación y medios n. 14.

Bou, G. (1997) El guión multimedia. Madrid: Amaya.

Bourdieu, P. (1997) Sobre la televisión. Barcelona: Anagrama.

Brée, J. (1995) Los niños, el consumo y el marketing. Barcelona: Paidós.

Bruner, J. (1996) Realidad mental y mundos posibles. Barcelona: Gedisa.

Calabrese, O. (1987) El lenguaje del arte. Barcelona: Paidós.

(1994) La era neobarroca. Madrid: Cátedra. 
Consejo Nacional de Televisión (1999) Telenovelas. Estudio comparativo de opinión. Santiago de Chile.

(1999b) Los noticieros televisivos. Un estudio cualitativo de opinión. Santiago de Chile.

(1999c) Informe de la televisión de pago en Chile. Santiago.

(1999d) Informe estadístico 1999. Santiago de Chile.

(2000) Informe estadístico 2000. Santiago de Chile.

(2000b) Emisión de programas, publicidad y continuidad. Santiago de Chile.

Cuadra, A. (2003) De la ciudad letrada a la ciudad virtual. Santiago de Chile: LOM.

Di Maggio, M. (1992) Escribir para televisión. Barcelona: Paidós.

Escarpit, R. (1985) “La televisión y la niñez”. Cuadernos de Comunicación n. 5.

Escudero, L.; Verón, E.; eds. (1997) Telenovelas. Ficción popular y mutaciones culturales.

Barcelona: Gedisa

Escudero, L. (1996) Malvinas: el gran relato. Barcelona: Gedisa.

, ed. (2001) La moda. Representaciones e identidad. Barcelona: Gedisa.

Fernández, M (1994) La dirección de producción para cine y televisión. Barcelona: Paidós.

Florenzano, R.; Molina, P. (1999) Televisión y niños. Santiago de Chile: CPU.

González, J. (1995) El discurso televisivo: espectáculo de la posmodernidad. Madrid: Cátedra.

González, J.; Ortiz, A. (1999) El spot publicitario. La metamorfosis del deseo. Madrid: Cátedra.

Grandi, R.; ed. (1997) Semiótica del marketing. Milano: FrancoAngeli.

Munizaga, Giselle; "Escenas Mediáticas de la Democracia”, en "La Pantalla Delirante”

Pakman, M.; comp. (1997) Construcciones de la experiencia humana. Vol. I y II. Barcelona: Gedisa.

Pasolini, P.P.; Metz, C.; Eco, U.; et al. (1969) Ideología y lenguaje cinematográfico. Madrid: Alberto Corazón Ed.

Piaget, J.; García, R. (1989) Hacia una lógica de significaciones. Barcelona: Gedisa.

Piscitelli, A. (1995) Cibercultura. Buenos Aires: Paidós.

(1998) Post-Televisión. Buenos Aires: Paidós.

Revista DeSignis n. 5 (2004). Monográfico “Corpus digitalis”.

Schramm, W.; Lyle, J.; Parker, E. (1965) Televisión para los niños. Barcelona: Ed. HispanoEuropea.

Souza, M.D. (1999) Consumo televisivo: percepciones y valoraciones. Santiago de Chile: Consejo Nacional de Televisión.

Souza, M.D.; Kurth, R. (2003) Informe 8/13 Tweens Chilenos. Santiago: Consejo Nacional de Televisión.

Verón, E.; comp. (1983) La centana electrónica: TV y comunicación. México: Eufesa.

Verón, E. (1998) La semiosis social. Barcelona: Gedisa.

Vilches, L. (1983) La lectura de la imagen. Barcelona: Paidós.

------- (1987) Teoría de la imagen periodística. Barcelona: Paidós.

(1989) Manipulación de la información televisiva. Barcelona: Paidós.

(1993) La televisión. Los efectos del bien y del mal. Barcelona: Paidós. 
Villain, D. (1997) El encuadre cinematográfico. Barcelona: Paidós.

VV.AA. (1996) Videoculturas de fin de siglo. Madrid: Cátedra.

Walter, E. (1994) Teoría de los signos. Santiago de Chile: Dolmen. 